\title{
Design and Development of the Online Examination System Based on B/S Structure
}

\author{
Hongmei Nie \\ Math,Physics and Information Engineering College \\ Zhejiang Normal University \\ Jinhua,China \\ e-mail:nhm@zjnu.cn
}

\begin{abstract}
Online examination is one of the crucial parts for online education. It is efficient and fast enough and reduces the large amount of material resource. An examination system is designed and developed based on web. This paper describes the principle of the system, presents the main functions of the system, analyses the algorithm of auto- generating test paper, and discusses the security of the system.
\end{abstract}

Keywords-online examination; algorithm; security; $B / S$ structure

\section{INTRODUCTION}

At present, the traditional test method is mainly based on paper. The shortcoming of this method is: overload of work, delay of statistics and evaluation, error-prone, etc. With the popularity of computer and the evelopment of the network, we need a new test platform to solve these problems.

Combined with the actual demand, we design and develop a set of simple, convenient, high maneuverability, safety good online examination system based on Web.

In this paper, the author will describe the principle of the online examination system, present the main functions of the system, analyse the algorithm of auto- generating test paper, and discuss the security of the system.

\section{THE PRINCIPLE OF ONLINE EXAMINATION SYSTEM}

The online examination system is based on $\mathrm{B} / \mathrm{S}$ structure, in which the traditional $\mathrm{C} / \mathrm{S}$ structure of the server is broken into the database server and application server, thus, $\mathrm{B} / \mathrm{S}$ structure constitute the three layer client/server architecture, as shown in figure 1 .

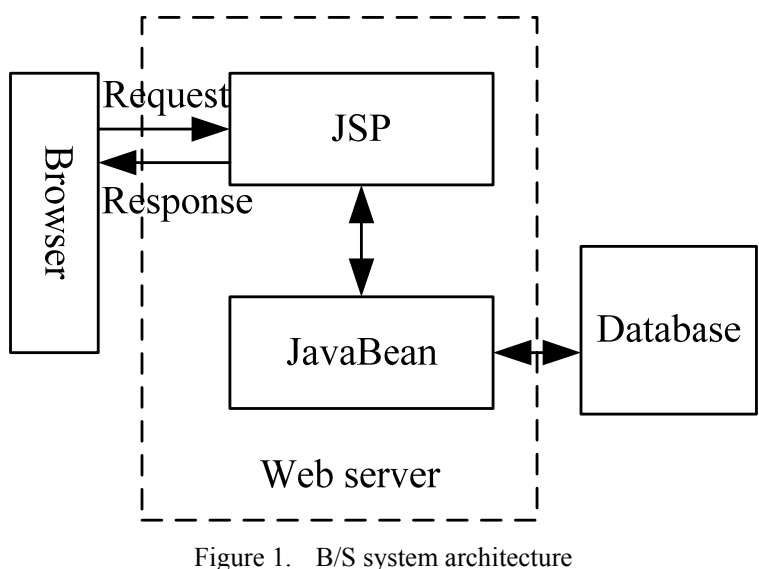

The first layer is the client, which is responsible for the connection between the user and the system as a whole. Client application programme is simplified to general the browser. The browser parses HTML data into illustrated pages, at the same time, through the web page can also realize the interaction. The user can submit requests through the form of web pages to the web server.

The second layer is web server. It responses to client requests by a specific treatment process, and produces a series the HTML code at runtime, at the same time, embeds the processed result in the generated HTML code, then sends the result to the client web browser. If the client requests data access, web server and database server will need to complete the task altogether[1].

The third layer is the database server, which is mainly responsible for receiving more requests from a web server, then returns the results to the application layer, so as to realize data management.

We design and develop the online examination system with JSP and SQL Server database technology.

\section{THE FUNCTIONS OF THE ONLINE EXAMINATION SYSTEM}

As shown in figure 2, roles of the online examination system have student, teacher and administrator. 


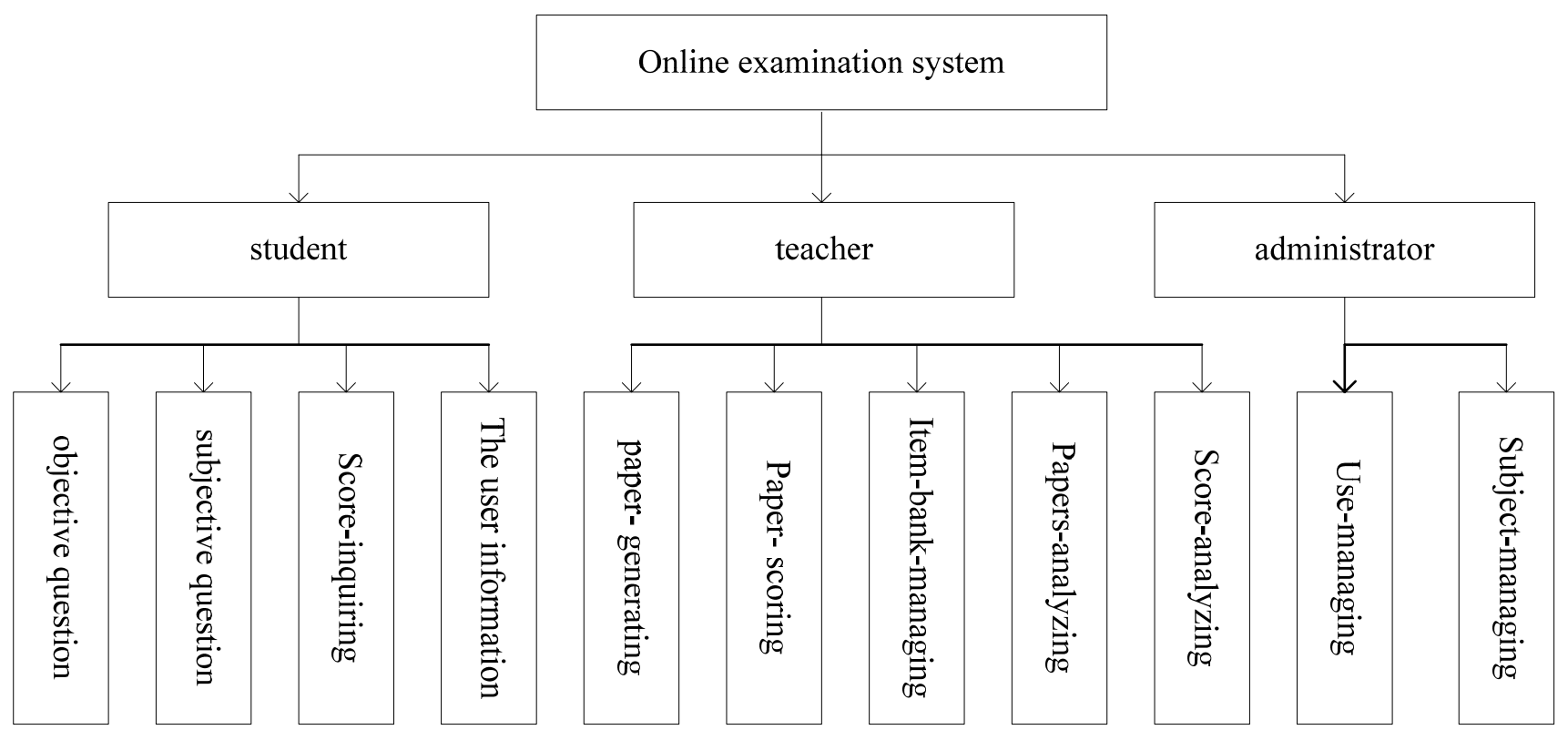

Figure 2. Function module diagram of online examination system

\section{A. Subsystem of Student}

\section{1) Objective question module}

At present, the system supports objective questions, such as single topic selection, multiple choice, and judgment question.

This module involves unit test and final examination.

Objective question module is the first part of tests that a student participates in. After students login in subject selection page, select the corresponding subject and type of tests, then the system will automatically jump to page of objective questions. In this page, students must finish the test within the given time. When students submit paper, the system will record their answers to the database and show about the correct answers and score of the objective questions.

In addition, the system sets the test time depending on the type of tests. The time is displayed on page of the test.

2) Subjective question module

At present, the system supports short answer question and essay question.

Subjective question module is the second part of tests that a student takes part in.It also involves unit test and final exam.

The subjective topic test is a kind of test that is arranged by teachers. When students submit paper, the system will record their answers to the database.

On the page of subjective topic test, the system uses the timer similarly.

3) Score-inquiring module

For objective question test, the system will give scores immediately when students submit answers. If questions on the paper are subjective, the teachers will send email to students after correcting the answers online.
Students also can login in the system to click the scores query button in the navigation bar. The system will jump to student achievement page. This page shows the students' grade of all the subjects, moreover, students can choose to view the details of each subject. Detailed page includes the scores of all kinds of questions.

4) The user information module

It shows teachers' information, studends' information, etc.

\section{B. Subsystem of Teacher}

\section{1) Paper-generating module}

The system randomly organizes questions to make up a test paper automatically.

According to their own needs, all the teachers can automatically extract the questions from the item bank to form a test paper by setting the parameters. These parameters are: question types, score of every type,degree of difficulty, and chapters, etc[2].

\section{2) Item-bank-managing module}

In this module, teachers can enter questions into item bank, modify, delete, and inquire questions.

3) Paper-scoring module

This module is one of the core functions of the online examination system. It includes automatic and manual mode.

The automatic mode needs to match the students' the correct answers. In the system, the types of objective questions are divided into single topic selection, multiple choice, and judgment question. According to the characteristics of the different types of questions, the system designs different matching algorithms of the correct answers and quickly calculates the student's test scores. At the end of the exam, the system will automatically give scores for 
students to look at in according to the students' answers[3][4].

In the manual mode, teachers correct subjective questions online. When the examination is over, teachers score students' answers and record scores into database.

4) Score-analyzing module

This module provides the score of each test about each student, and displays the scores of all kinds of questions. With this module, students can learn about their weaknesses and advantages in detail.

\section{5) Papers-analyzing module}

The system automatically generates statistical results of each exam, including score distribution, total score, and average score, which can help teachers master the study state of all the students. On the basis of these results, teachers can change teaching strategies, and improve teaching methods[5].

\section{Subsystem of Administrator}

The following are the main function modules of the subsystem.

\section{1) Subject- managing module}

In this module, teachers can create new examination subjects and administrators can manage all the subjects.

2) User -managing module

The online examination system involves students, teachers, and administrators. Only the administrators have the authorities of user management.

\section{ALGORITHM OF AUTO-GENERATING PAPER}

The algorithm of automatically generating paper is an important part of the online examination system. Common algorithms of generating paper are: random algorithm, heuristic algorithm, genetic algorithm. This system adopts the random algorithm for generating paper. The following is the specific process of algorithm realization, as shown in figure 3.

Parameters of a paper are: question types, score of every type, degree of difficulty, and chapters, etc.

\section{SYSTEM SECURITY}

Online examination system as an important part of the assessment of students' learning outcomes, which needs to be confidential to the examinee and the related questions. The related data and operation must ensure the safety of the whole system.

For system operators, administrators need to assigns different operating authority. Before operating, the system need to authenticate the user's access. Only an operator with corresponding rights is allowed to related operations; otherwise, his operations are refused. In addition, the system interfaces of the user are not allowed to access or operate are hidden. In order to ensure the data security of the system, it is necessary to strengthen the security of database management system, preventing illegal data destruction and loss of important data. In database security, mandatory access control and custom access control need to be implemented. The system assigns different user roles for different database users, and grants the permissions for user

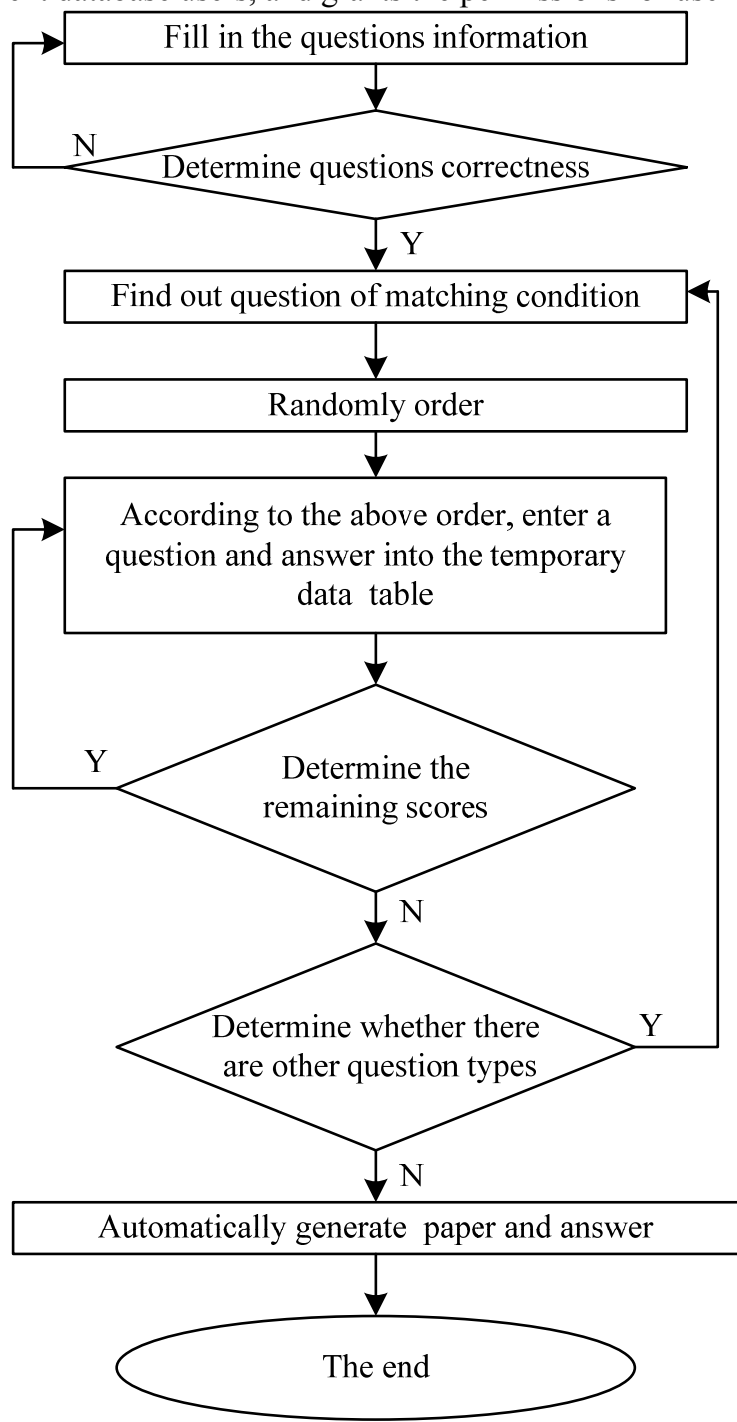

Figure 3. The flow diagram of generating paper

roles of the system. In addition, the system needs to strengthen the management of user access permissions. Only a specific permission operator can do the corresponding operation. The system needs to adopt two methods of access control and network control, ensuring no unauthorized access to the whole system and no illegal use to each function.

\section{SUMMARY}

We design and develop the online examination system. This system overcomes the defects of the traditional detection method based on paper, and improves the efficiency of learning and testing. Of course, functions of the system is not perfect. We are constantly expanding and improving functions of the system. 


\section{REFERENCES}

[1] Liang Shi-qing, SUN Bo-cheng. Research and Implementation of Remote Examination System Based on Java[J]. Modem Computer,2009,(2):192-194.

[2] Tu Zhi-qing.Design and discussion of generation system of random test paper[J]. Fujian Computer,2008,(7):161-170.

[3] Guo Dong-mei. Design and Realization of a Network Test System based onWeb. Development and Application of the Computer[J], $2011,(24): 65-72$.
[4] Yuan Zhenming, Zhang Liang,Zhan Guohua. A NOVEL WEB-BASED ONLINE EXAMINATION SYSTEM FOR COMPUTER SCIENCE EDUCATION[J]. 33'd ASEE/IEEE Frontiers in Education Conference, 2003 , pp: S3F_7 - S3F_10.

[5] Xiao Jian-qing ,etc.Key technologies in development of paper analysis system. Computer Engineering and Design [J], 2008,29(7) : $1847-1849$ 